\title{
ANALISIS PERHITUNGAN PENERIMAAN DAN PENYETORAN PAJAK PENERANGAN JALAN DI KABUPATEN TANA TORAJA
}

\author{
Griya Clara Kaparang ${ }^{1}$, Winston Pontoh $^{2}$, I Gede Suwetja ${ }^{3}$ \\ 1,2,3 Jurusan Akuntansi, Fakultas Ekonomi dan Bisnis, Universitas Sam Ratulangi, Jl. Kampus Bahu, Manado, \\ 95115, Indonesia \\ E-mail : clarakaparang16@gmail.com
}

\begin{abstract}
Road Lighting Tax is one of the regional revenues whose revenues are very important for future improvement efforts. The purpose of this study is to find out whether the calculation of receipt and deposit of street lighting tax in Tana Toraja Regency is in accordance with the rules set or not, and the potential for acceptance and effectiveness. This research uses descriptive qualitative research. The results showed that the calculation of the receipt and deposit of street lighting tax in Tana Toraja Regency had proceeded with the rules set by the regional government, and the potential for its revenue and effectiveness in 2016-2017 had increased very well.

Keywords: Street Lighting Tax, Street Lighting Tax Calculation, Potential for Acceptance, Effectiveness.
\end{abstract}

\section{PENDAHULUAN}

Pajak adalah salah satu sumber penerimaan negara. Pendapatan asli daerah yang salah satunya berupa pajak daerah yaitu pajak penerangan jalan. Dengan semakin besarnya kebutuhan untuk melaksanakan pemerintahan di Kabupaten Tana Toraja, maka diperlukan upaya untuk semaksimal mungkin dalam memperhatikan perhitungan PPJ, menggali potensipotensi sumber penerimaan dan penyetoran pajak penerangan jalan yang agar dikelompokkan berdasarkan kode golongan pelanggan.

\section{TINJAUAN PUSTAKA}

\section{Konsep Pajak}

Pengertian Pajak. Pajak merupakan iuran wajib dari masyarakat pada Negara yang didasarkan atas undang-undang dengan sifat dapat dipaksakan guna membiayai kegiatan Negara untuk kepentingan umum (Mardiasmo, 2018:7).

Pengelompokan Pajak. Menurut Mardiasmo (2018:7) pajak yang dipungut dikelompokkan berdasarkan golongan, sifat, dan lembaga pemungut.

\section{Konsep pajak daerah}

Pengertian pajak daerah. Pajak daerah merupakan iuran wajib dari masyarakat yang dipungut oleh daerah berdasarkan peraturan daerah yang bersifat memaksa tanpa memiliki imbal balik dengan tujuan untuk membiayai pengeluaran daerah.

Pajak penerangan jalan. Pajak penerangan jalan didasarkan pada penggunaan listrik yang digunakan untuk menerangi jalanan umum dan seluruh biayanya ditanggung oleh pemerintah daerah. Tarif pajk penerangan jalan oleh pemerintah pusat ditetapkan paling tinggi 10\%, dan untuk pada pelaksanaan kegiatan pertambangan dan gas alam sebesar $30 \%$.

Objek pajak penerangan jalan. Objek pajak ini adalah listrik yang dihasilkan sendiri dan yang diterima dari sumber lain.

Bukan objek pajak penerangan jalan. Tidak termasuk objek dalam pajak ini adalah penggunaan listrik oleh lembaga pemerintah pusat dan lembaga pemerintah daerah, kedutaan, 
konsulat, dan perwakilan asing, atau kapasitas tertentu yang tidak memerlukan ijin dari instansi teknis terkait seperti yang diatur oleh pemerintah daerah seperti tempat ibadah dan panti asuhan.

Subjek pajak dan wajib pajak penerangan jalan. Sebjek PPJ adalah semua yang menggunakan tenaga listrik.

Dasar pengenaan, tarif, dan cara perhitungan pajak penerangan jalan. Dasar pengenaan pajak ini adalah nilai jual tenaga listrik, dimana tarif pajak ditetapkan paling tinggi sebesar 10\%. Rumus penghitungan pajak ini adalah :

Pajak langsung $=$ tarif pajak $\mathrm{x}$ dasar pengenaan pajak $=$ tarif pajak $\mathrm{x}$ nilai jual tenaga listrik

\section{Potensi dan efektivitas pajak penerangan jalan}

Potensi pajak penerangan jalan. Potensi adalah kemampuan dasar yang dimiliki seseorang yang masih bisa dikembangkan.

Efektivitas pajak penerangan jalan. Efektivitas adalah suatu alat pengukur keberhasilan suatu perusahaan dalam mencapai tujuannya.

\section{METODE PENELITIAN}

Jenis Penelitian. Jenis penelitian dalah penelitian kualitatif, jenis penelitian ini memeberikan pemahaman dan persepsi secara rinci untuk menjelaskan objek study dan untuk mendapatkan hasil yang berdasarkan datayang diperoleh.

Tempat dan Waktu Penelitian. Penelitian ini dilakukan di PT. PLN Persero Area Palopo dan Badan Pendapatan Daerah Tana Toraja. Waktu pelaksanaan pnelitian dimulai pada Juli 2018 sampai selesai.

Jenis data. Penelitian ini menggunakan dua jenis data yaitu kualitatif dan kuantitatif.

Metode pengumpulan data. Teknik pengumpulan data ini dilakukan peneliti untuk memperoleh data dimana data tersebut akan digunakan sebagai bahan pertimbangan pengambilan keputusan yang nantinya dapat dipertanggung jawabkan.

Sumber data. penelitian ini menggunakan data primer, yaitu wawancara dan dokumentasi yang dilakukan secara langsung dengan kepala PT. PLN Persero Area Palopo dan kepala Badan Pendapatan Daerah Kabupaten Tana Toraja mengenai pajak penerangan jalan.

Metode dan proses analisis. Metode analisis yang digunakan dalam penelitian ini adalah metode analisis deskriptif kualitatif. Adapun tahap-tahap analisi data dalam penelitian ini yaitu sebagai berikut :

1. Tahap pertama, peniliti mengumpulkan data melalui proses wawancara

2. Tahap kedua, setelah mengumpulkan data peneliti memilih hala-hal pokok yang sesuai dengan fokus penelitian.

3. Tahap ketiga, peneliti menggunakan data- data tersebut untuk membandingkan apakah data-data tersebut telah sesuatu dengan aturan yang ditetapkan atau tidak.

4. Tahap keempat, peneliti mulai mengambil dan membuat kesimpulan berdasrkan hasil perbandingan pada tahap ketiga. 


\section{HASIL PENELITIAN DAN PEMBAHASAN}

\subsection{Hasil Penelitian}

Tabel 1. Pendapatan Asli Daerah (PAD) Kabupaten Tana Toraja

\begin{tabular}{ccc}
\hline Tahun & Target PAD (Rp) & Realisasi PAD (Rp) \\
\hline 2016 & 93.231 .216 .000 & 101.993 .901 .924 \\
2017 & 150.563 .647 .813 & 141.777 .906 .547 \\
\hline
\end{tabular}

Sumber : Badan Pendapatan Daerah Kab. Tana Toraja, 2018

Tabel 2. Pendapatan Pajak Daerah Kabupaten Tana Toraja

\begin{tabular}{ccc}
\hline Tahun & Target $(\mathbf{R p )}$ & Realisasi (Rp) \\
\hline 2016 & 6.658 .815 .000 & 7.336 .005 .910 \\
2017 & 10.500 .000 .000 & 9.211 .461 .706 \\
\hline
\end{tabular}

Sumber : Badan Pendapatan Daerah Kab. Tana Toraja, 2018

Tabel 3. Pajak Penerangan Jalan di Kabupaten Tana Toraja

\begin{tabular}{ccr}
\hline Tahun & Target $(\mathbf{R p})$ & \multicolumn{1}{c}{ Realisasi (Rp) } \\
\hline 2016 & 2.500 .000 .000 & 3.101 .033 .892 \\
2017 & 4.000 .000 .000 & 3.912 .200 .431 \\
\hline
\end{tabular}

Sumber : Badan Pendapatan Daerah, 2018

Penyetoran Pajak Penerangan Jalan di Kabupaten Tana Toraja. Penyetoran PPJ di Kabupaten Tana Toraja dilakukan pada bulan berikutnya. Pihak PLN membuat daftar rekapitulasi listrik yang dikelompokkan berdasarkan kode golongan pelanggan.

\subsection{Pembahasan}

Perhitungan Pajak Penerangan Jalan

Perhitungan Pajak Penerangan Jalan

Kwh $\quad=$ pemakaian listrik bulan - pemakaian listrik bulan lalu $\mathrm{X}$ $\mathrm{Rp} / \mathrm{kwh}$

Biaya beban rekening listrik $=\mathrm{kwh} \times \mathrm{Rp} / \mathrm{kwh}$

$=$ Daya $/ 1000 \times$ biaya beban TDL

Pajak Penerangan Jalan $(\mathrm{PPJ})=10 \% \mathrm{x}$ biaya beban rekening listrik

Total Tagihan $\quad=\mathrm{PPJ}+$ biaya beban rekening listrik

Contoh Perhitungan Pajak Penerangan Jalan :

Rekening Listrik

Tarif/Daya

Stand akhir bulan berjalan

Stand akhir bulan lalu

Kwh

Biaya beban rekening listrik :

$$
\begin{aligned}
& =18 \mathrm{kwh} \times \mathrm{Rp} 1.352 \\
& =\operatorname{Rp} 24.336
\end{aligned}
$$

Pajak Penerangan Jalan :

Total Tagihan :

$$
\begin{aligned}
& =10 \% \times \mathrm{Rp} .24 .336 \\
& =\operatorname{Rp} 2.433,6
\end{aligned}
$$

$$
\begin{aligned}
& =\operatorname{Rp} 24.336+\operatorname{Rp} \cdot 2.433,6 \\
& =\operatorname{Rp} 26.798,6
\end{aligned}
$$


Tabel 4. Potensi penerimaan pajak penerangan jalan

\begin{tabular}{lrrr}
\hline \multicolumn{1}{c}{ Golongan } & Basis PPJ & Tarif PPJ & \multicolumn{1}{c}{ Potensi } \\
\hline Sosial & 118.923 .941 & $10 \%$ & 11.892 .394 \\
Rumah Tangga & 2.311 .375 .135 & $10 \%$ & 231.137 .513 \\
Bisnis & 468.579 .395 & $10 \%$ & 46.857 .939 \\
Industri & 18.696 .656 & $3 \%$ & 560.899 \\
Publik & 37.175 .194 & $10 \%$ & 3.171 .519 \\
Layanan Khusus & 39.306 .611 & $10 \%$ & 3.930 .611 \\
& & Jumlah & 297.550 .875 \\
\hline
\end{tabular}

Sumber Data : PT. PLN Persero Area Palopo, Data diolah

Tabel 5. Potensi penerimaan pajak penerangan jalan

\begin{tabular}{lccc}
\hline \multicolumn{1}{c}{ Golongan } & Basis PPJ & Tarif PPJ & Potensi \\
\hline Sosial & 121.142 .117 & $10 \%$ & 12.114 .211 \\
Rumah Tangga & 3.178 .234 .922 & $10 \%$ & 317.823 .492 \\
Bisnis & 509.808 .066 & $10 \%$ & 50.980 .806 \\
Industri & 182.231 .384 & $3 \%$ & 5.466 .941 \\
Publik & 35.443 .566 & $10 \%$ & 3.544 .356 \\
Layanan Khusus & 41.648 .053 & $10 \%$ & 4.164 .805 \\
& & Jumlah & 394.094 .611 \\
\hline
\end{tabular}

Sumber Data : PT. PLN Persero Area Palopo, Data diolah

Tabel 6. Efektivitas Pajak Penerangan Jalan

\begin{tabular}{cccrc}
\hline Tahun & $\begin{array}{c}\text { Realisasi } \\
\text { Penerimaan } \\
\text { PPJ }(\mathbf{R p})\end{array}$ & $\begin{array}{c}\text { Potensi PPJ } \\
(\mathbf{R p})\end{array}$ & Efektivitas & Interpretasi \\
\hline 2016 & 3.101 .033 .892 & 297.550 .875 & $104,2 \%$ & Sangat efektif \\
2017 & 3.912 .200 .431 & 394.094 .611 & $9,93 \%$ & Cukup efektif \\
\hline
\end{tabular}

Sumber : Badan Pendapatan Daerah Kab. Tana Toraja, Data diolah

\section{KESIMPULAN DAN SARAN}

\subsection{Kesimpulan}

Dari perhitungan penerimaan dan penyetoran berdasarkan PT. PLN Persero pajak penerangan jalan di Kabupaten Tana Toraja telah berjalan sesuai dengan aturan yang telah ditetapkan oleh pemerintah daerah. Berdasarkan perhitungan potensinya masih memiliki selisih yang besar antara potensi dan realisasi. Jumlah pemungutan penerimaan pajak penerangan jalan untuk tahun 2016-2017 mengalami peningkatan yang sangat baik, dimana efektifitas pajak penerangan jalan telah mencapai $100 \%$.

\subsection{Saran}

Dilihat dari penerimaan pajak penerangan jalan yang mengalami peningkatan yang sangat baik dan dapat dikatakan pendapatan daerah yang besar, maka pemerintah kabupaten Tana Toraja dapat lebih memperhatikan pemungutan pajak penerangan jalan. Pihak PT. PLN (Persero) dan pemerintah Kabupaten Tana Toraja kiranya dapat berkomunikasi dengan baik mengenai pajak penerangan jalan agar dapat berjalan lebih baik lagi kedepannya. 


\section{DAFTAR PUSTAKA}

Andayani, 2014. Correlation Analysis Between The Improvement Tax with Tourism Development in the Lovina Singaraja Area (Case Study In The Buleleng District). Internationa Journal of bussines, Economics, and Law. Universitas Pendidikan Ganesha.

Astamira, A. 2012. Analisis Kinerja dan Potensi Pajak Penerangan Jalan di Kota Surakarta. Skirpsi. Universitas Sebelas Maret. Surakarta.

Brotodiharjo, R. Santoso, 2013. Pengantar Ilmu Hukum Pajak. PT Refika Aditama. Bandung. Haidasari, A. 2015. Analisis Mekanisme Pajak Penerangan Jalan Pada PT. Pertamina (Persero) RU IV Cilacap. Tugas Akhir. Universitas Gadjah Mada. Yogyakarta.

Mardiasmo, 2011. Perpajakan. C.V Andi OFFSET. Jakarta.

Marsuri, F. Alam. 2015. Akuntansi dan Pajak. http://akuntansi Praktek.blogspot.com /2015/04/a.html. Diakses pada tanggal 14 April 2015.

Rakhmatika, Y. 2017. Analisis Kinerja Penerimaan Pajak Penerangan Jalan (Study Kasus di Kabupaten Bantul Tahun 2012-2016). Tugas Akhir. Universitas Gadjah Mada. Yogyakarta.

Sugiyono, 2011. Metodology Penelitian Kuantitatif Kualitatif. Alfabeta. Bandung.

Triana, M. 2008. Analisis Hubungan Antara Pajak Penerangan Jalan Umum dan Alokasi Dana Penerangan Jalan Umum. Skripsi. Universitas Sanata Dharma. Yogyakarta.

Widyaningsih, 2016. Effectiveness Of Street Lighting Tax Collection, Tax On The Regional Revenue Office Of Makassar. Skripsi. Sekolah Tinggi Ilmu Manajemen Nitro Makassar. 